\section{Salami Science in the Age of Open Data: Déjà lu and Accountability in Management and Business Research}

Salami Science na Era do Open Data: Déjà lu e Accountability na Pesquisa em Gestão e Negócios
Wesley Mendes-Da-Silva 1,2

Cristiana Cerqueira Leal ${ }^{3}$ ()

\section{INTRODUCTION}

The growth in the number of scientific research articles that are daily made available to society through their publication in scientific journals has been explicit. In fact, as illustrated by Table 1, in 2018 approximately 2.6 million scientific articles were published, which suggests an annual growth in the area of $3.8 \%$ since 2008. During this period, while economically developed countries such as the United States, Germany, the United Kingdom, and Canada have presented annual growth rates inferior to the world average $(0.71 \%, 1.28 \%, 0.67 \%$, and $1.19 \%$ respectively), there has been a significant percentage growth in the number of publications in economically emerging countries - including the annual growth rates of China (7.81\%), India (10.73\%), Russia (9.88\%), Brazil (5.42\%), and Iran $(10.99 \%)$.
1. Fundação Getulio Vargas, Escola de Administração de Empresas de São Paulo, São Paulo, SP, Brazil.

2. Editor-in-chief of the Journal of Contemporary Administration (RAC).

3. Escola de Economia e Gestão, Universidade do Minho, Braga, Portugal.
A priori this growth is very positive, since scientific publications continue to be the best way to validate knowledge and for the authors to receive recognized credit (Bell, Hill, \& Lehming, 2007). However, it imposes a group of equally growing costs. We can highlight not just financial costs, but also costs that tend to be forgotten, such as more and more onerous workloads for evaluators and the allocation of resources to process submissions (yes, there is a considerable cost in these activities). Examined together with observed conditions of stocks and flows, it appears reasonable to examine and maintain under observation the sustainability of scientific publication as we know it, especially in terms of open access. The field of management and business, like other fields of knowledge, is subject to these preoccupations (Karabag \& Berggren, 2016), and the Journal of Contemporary Administration (RAC) shares these concerns. 
Table 1. Articles written in all fields of knowledge for the 15 most prolific countries, regions, or economies in the world from 2008 to 2018.

\begin{tabular}{|c|c|c|c|c|c|c|}
\hline Rank & $\begin{array}{l}\text { Region, country, } \\
\text { or economy }^{(\mathrm{a})}\end{array}$ & $2008^{(b)}$ & $2018^{(\mathrm{c})}$ & $\begin{array}{l}\overline{\text { Annual } \Delta \%} \\
2008-2018^{(\mathrm{d})}\end{array}$ & $\begin{array}{l}\text { Proportion of } \\
\text { world production } \\
\quad \text { (\%) } 2018^{(\mathrm{e})}\end{array}$ & $\begin{array}{l}\text { Cumulative } \\
\text { proportion of } \\
\text { world production } \\
(\%) 2018^{(f)}\end{array}$ \\
\hline- & World & $1,755,850$ & $2,555,959$ & 3.83 & - & - \\
\hline- & European Union & 528,938 & 622,125 & 1.64 & 24.34 & - \\
\hline 1 & China & 249,049 & 528,263 & 7.81 & 20.67 & 20.67 \\
\hline 2 & United States & 393,979 & 422,808 & 0.71 & 16.54 & 37.21 \\
\hline 3 & India & 48,998 & 135,788 & 10.73 & 5.31 & 42.52 \\
\hline 4 & Germany & 91,904 & 104,396 & 1.28 & 4.08 & 46.61 \\
\hline 5 & Japan & 108,241 & 98,793 & -0.91 & 3.87 & 50.47 \\
\hline 6 & United Kingdom & 91,358 & 97,681 & 0.67 & 3.82 & 54.29 \\
\hline 7 & Russia & 31,798 & 81,579 & 9.88 & 3.19 & 57.49 \\
\hline 8 & Italy & 56,157 & 71,240 & 2.41 & 2.79 & 60.27 \\
\hline 9 & South Korea & 44,094 & 66,376 & 4.17 & 2.60 & 62.87 \\
\hline 10 & France & 66,460 & 66,352 & -0.02 & 2.60 & 65.47 \\
\hline 11 & Brazil & 35,490 & 60,148 & 5.42 & 2.35 & 67.82 \\
\hline 12 & Canada & 53,296 & 59,968 & 1.19 & 2.35 & 70.17 \\
\hline 13 & Spain & 44,191 & 54,537 & 2.13 & 2.13 & 72.30 \\
\hline 14 & Australia & 37,174 & 53,610 & 3.73 & 2.10 & 74.40 \\
\hline 15 & Iran & 17,034 & 48,306 & 10.99 & 1.89 & 76.29 \\
\hline
\end{tabular}

Note. Source: White, K. (2019). Publication output, by region, country, or economy. Science \& Engineering Indicators. Retrieved from https://ncses.nsf.gov/pubs/nsb20206/publication-output-by-region-country-or-economy. ${ }^{(a)}$ The countries or economies are classified based on the total in 2018. The number of articles refers to peer-reviewed journal articles and conference annals since the indexation of Scopus. (b) ${ }^{(c)}$ The articles are classified by year of publication and attributed to a region based on the institutional addresses of the authors listed in the article. The proportions are based on the world total, excluding non-classified addresses (data not presented). The data collected is related to June 2019. (d) Average annual variation or composite growth rate during these years, given by: ${ }^{(e)}$ Proportion of articles from this location; ${ }^{(\mathrm{f})}$ Cumulative production of articles from these locations.

$\overline{\text { Annual } \Delta \%}=\left(\left(\frac{\# \text { of publications in year } y}{\# \text { of publications in year } y-n}\right)^{\frac{1}{n}}\right)-1$;

As highlighted in a previous editorial (MendesDa-Silva, 2018a), despite the fact that most researchers who act as evaluators are not remunerated for their contributions to the editorial process, this does not signify that the editorial process occurs without costs. That is, the time spent by researchers revising submissions is not spent in teaching or research. Therefore, the time spent on scientific articles that contribute little to the construction of new scientific knowledge is wasted. Most of the journals have rigid editorial policies against duplicate publication. The application of these policies is directed toward those cases in which there is a substantial duplication of data and/or text in different works.

We believe that there are three main factors that contribute to the increase of publications which need analysis: the number of publications with a considerable number of authors (Adams, Pendlebury, Potter, \& Szomszor, 2019), the growth of plagiarism (Eden, Dean,
\& Vaaler, 2018) and the appearance of predatory journals (Rupp, Anastasopolou, Wintermeyer, Malhaan, El Khassawna, \& Heiss, 2019).

In the study "Multi-Authorship and Research Analytics" for the Institute for Scientific Information, Adams, Pendlebury, Potter and Szomszor (2019) identify a growing number of articles with more than 10 authors and the existence of articles with 1,000 or more authors of more than a hundred different nationalities. According to the same study, even though most of the articles published (95\%) have 10 or fewer authors, there has been a greater growth in publications with more than 10 authors, comparing the periods from 2009 to 2013 to the period 2014 to 2018 . Equally but with greater growth there has been an increase in the number of publications involving authors from more than 40 countries. 
Eden, Dean and Vaaler (2018) argue that individuals who are active in scientific research tend to commit plagiarism when three conditions occur: opportunity, incentive, and rationalization, which these authors call the fraud triangle (Cressey, 1953). According to these authors, the first aspect becomes viable when there is an asymmetry of information and ambiguity together with a lack of monitoring and enforcement (Stuebs \& Wilkinson, 2010). The second vertex of the fraud triangle is centered on an individual being able to identify financial or social incentives to commit frauds. The third vertex consists of rationalizing the act as consistent with the researcher's code of ethics. Thus, depending on the understanding that this behavior is consistent with the practices and norms viewed as normal, the individual may feel disposed to commit certain acts contrary to the ethics of scientific research. And moreover, there is also the possibility of intentionally and strategically modifying the interpretation of the norms, in order to make unethical acts viable.

In terms of the conditions pointed out by the structure of the fraud triangle, we would like to point out that monitoring is typically reduced, limited to checkbox mechanisms that the authors need to meet during the act of submission, in addition to plagiarism detecting software, such as iThenticate. The opportunity for fraud may also be emphasized due to reduced enforcement. That is, the frequency of penalties for inadequate behavior could be the subject of attention of journals interested in initiating behavior that is not entirely understood to be part of best ethical practices. As highlighted by Honig, Lampel, Siegel and Drnevich (2014), journals at the top of the fields of knowledge related to the social sciences should dedicate more attention to questions related to the ethical behavior of their authors. Thus, editors and reviewers should develop and practice abilities related to the 'trust, but verify' principle (to use an expression adopted by a recent $R A C$ editorial: "Science should be Show Me, not Trust Me", Mendes-Da-Silva, 2019b), to protect the integrity of the editorial process.

In addition to the increase of articles published, there has also been an increase in predatory journals (Rupp et al., 2019). That is, journals that, through the payment of a fee, rapidly publish any article. In Brazil, Perlin, Imasato and Borenstein (2018) analyzed publication during the period from 2000 to 2015 and concluded that even though predatory journals are a small percentage of all journal publications, they have been growing exponentially. It has also been verified that investigators with non-indexed publications who have obtained their $\mathrm{PhD}$ locally have a greater chance of publishing in predatory journals (Pohlmann, 2019).
The dividing line between works that deliver a significant contribution to a given field of knowledge and those that can be seen merely repackaging data that is rarely well-defined, and require that editors and evaluators be sufficiently informed about the relevant aspects of the editorial process involving the submitted work (Camargo, 2013). It is for this reason that the $R A C$ will now demand that all authors inform it whether the data utilized in submitted research was utilized in a recently published work in another locale, which can have some relevance to the submitted work. More obviously, these procedures depend on the integrity of the authors. The final motivation is to increase the rigor of looking through the works that may contribute to the field of knowledge, inhibiting salami science.

In situations in which the authors did not appropriately report the state of the art, they deprived the editors and evaluators of an opportunity to gauge the effective extent of the contribution of correlated knowledge. Also, in this respect, the insufficient detailing of the current relevant literature related to the addressed theme not only distorts the frontiers of the investigated field, but also omits relevant information. It is reasonable to accept that it is getting more and more difficult to be completely aware of all recent relevant scientific publications as well as those that have not yet been published, which are available as working papers in various channels (like conference proceedings and repositories: SSRN and ResearchGate, among others). Moreover, in these situations in which authors omit a reference to their own work, the understanding of the editors and reviewers cannot go very far beyond dishonest behavior that wounds the principle of accountability in research (Camargo, 2013; Wawer, 2019).

It is reasonably unlikely that someone will deny his or her desire to publish new results as rapidly as possible, and there is nothing illegitimate in this desire. In parallel, the desire to do this just to increase the number of publications, dividing research into articles with marginal or minimal contributions, comes to configure behavior that is explicitly not very legitimate. Editors and evaluators (which are essentially our own peers) around the world have come to dedicating attention to issues regarding this phenomenon. After all, how many articles can be published based on a single research project (Jackson, Walter, Daly, \& Cleary, 2014; Watson et al., 2014)? 


\section{WHAT IS SALAMI SCIENCE?}

According to Elstein, Cadmus, Pitkin, Mundy and McDowell (1998), salami science essentially signifies reporting the results of a single study in two or more articles. This signifies that research efforts are divided or sliced into different articles responding to questions of different investigations about the same subject and using the same data. Segmentation per se is not a bad scientific practice and, sometimes, it is even necessary, namely in studies of smaller scale with various research questions and methodological approaches. For example: (a) when various parts of a study (including the results) can be of interest to different audiences. In situations like this, if the article is not sliced up, and as a result is published in more than one version, part of the audience could end up missing relevant knowledge; (b) when the study deals with various dimensions of a problem that is to extensive and intricate to be published within a single article.

Salami science occurs when the same authors, using the same data (or very similar data), produce various publications about the same subject, with low marginal contributions, with the objective being to increase their number of publications (Britigan, Strauss, \& Susman, 2010; Engle, 2018; Feeg, 1992; Hoit, 2007; Nature Materials, 2005; Smolčić, 2013).

Thus, the segmentation of research in various scientific articles requires heightened scrutiny, increasing the work associated with peer review; the scientific journals require time dedicated to editorial processing. To reviewees, it requires time to analyze overlapping with other publications by the same authors on the same subject using the same data, which could be used to evaluate studies that present new data or results for readers, possibly causing the loss of time that could be spent reading really new and original studies, instead of having to read various publications by the same authors to mount a jigsaw puzzle of the small marginal contributions of each of them.

\section{WHY DOES SALAMI SCIENCE OCCUR?}

In part, salami science can occur not due to the intrinsic intention of researchers to maximize their count of publications, but rather the incentives and conditions of the context where they work. For example: the criteria of attributing financing for investigation projects (which fundamentally value the number of publications as output) and the hiring of professors and investigators based on their number of publications. Under a publish or perish atmosphere that has increased over the past few decades, the excessive emphasis on the volume of publication as the proxy to evaluate scientific production inevitably rewards quantity over quality. As a consequence, rather than commit themselves to more demanding review procedures in high quality journals, authors may opt to divide their research into various publications for lower quality journals with more benevolent review and acceptance processes.

This practice by some investigators may be due basically to three factors, at least in the view of Elstein et al. (1998): (a) the pressure to publish or perish, which may imply the researchers losing their positions, their potential mandate, and even their job; (b) the increase in their appeals to convince stimulation agency evaluators, which may encourage researchers to increase their number of publications; (c) the protection of financial interests due to a research product, even before it becomes commercial: researchers may feel the need to seek to increase their number of articles and citations to legitimate their position as owners and deserving of financial rewards associated with this product.

This does not mean, however, that the only criterion of evaluation for researchers and research institutions is or should be the volume of scientific articles published. Nonetheless, it would be naïve if professors, particularly those who are just beginning their scientific careers, were not aware of the dictum publish or perish. We should also underline the role of defining institutional evaluation policies with broader qualitative dimensions that are up to the players in the scientific research environment (Camargo, 2013; Tarrant, 2017). Researchers, especially the more experienced seniors, should be evaluated by the regulation of the research institution, regulations that should stimulate the concept and execution of politics designed to inhibit salami science.

First, the journal editors should declare in their instructions to the authors that their journals generally do not accept more than one article from the same study. Second, the authors should divulge all of the possible similar publications, published abstracts, similar articles, and parts of the same study that were published in other places (or if everything was published in other places). This is the reason why Nature Materials explicitly requires that all authors supply details and preprints of all the works that are being considered, in the press or recently published in another place, which could have some relevance to the work being submitted. In the final analysis, however, this depends on the integrity of the authors.

\section{OPEN DATA, THE REUSE OF DATA, AND CONTRIBUTIONS TO THE LITERATURE}

The practice of open data, in addition to inhibiting salami science by the original authors, makes it possible 
to scrutinize other publications through the possibility that other investigators could replicate a study, especially when these raise doubts about the level of the results. Thus, more practices of investigation, either at the level of their treatment or the respective results, are easily identified. An example of this occurred in June 2020 when the prestigious journals New England Journal of Medicine and The Lancet annulled the publication of two studies related to COVID-19, in function of the data being judged to be of low quality, or not very trustworthy (Davey, 2020; Gomes, 2020).

There is a growing clamor around the world in the name of open data. The list of motivations for this reason include research transparency, the viability of new research based on the reuse of data for new studies and teaching activities, reducing the cost of the realized research, among other expected benefits. However, in encouraging the practice of open data, such as the reuse of data, we should not confuse open science practices with incentives for salami science.

That is, the reuse of published data, which usually has already been used in previous studies (qualitative or quantitative), should occur due to one of the main concerns, and should receive balanced attention and simultaneous recognition of the database sources and the proper citation of works that have already used the data for correlated studies (Irwin \& Winterton, 2012). With this, it is expected that we will not incur the multiplicity of the articles that merely replicate previous studies, as if these do not exist. It is the duty of the authors to transparently and completely register the data source and the references that use this data within the subject of the study. As a consequence, the authors will have appropriately presented the state of the art, allowing for the study's contribution to be faithfully argued.

The $R A C$ has published articles with open data, in line with the international trends in defense of open science and all of their motivators and expected results. In addition, the $R A C$ is open to works supported by the reuse of data utilized in already published studies. But it is imperative that the authors make the proper, honest, and transparent registry of the origin of the data, the state of the art, and the effective contribution that their work delivers compared to previous works. And, in this sense, we understand that we are contributing to inhibit salami science, by not ignoring that a group of articles could end up being improperly published based on the same research effort. This merely for the purpose of increasing the count of published articles, even if they are redundant in terms of the result, and basically without explicit contributions to the field of knowledge for which they are being considered.

The evolution of the number of articles with open data in recent years is undeniable. If we consider the works published in the Public Library of Science (Figure 1 ), we can note that the quantity of articles that have been sharing data since 2014 is decreasing.

Even though there is a strong trend toward sharing scientific research data, based on which ample liquid benefits are expected for society, there are also researchers who are worried about the lack of resources and incentives to share their research data. Some understand that there is an incremental force to publish data when the articles are published. However, this occasional extra effort can be really seen as an investment and not a cost. It is a more reliable and reusable research investment for the scientific community. In addition, it would be an investment in the reputation of the individual researcher, given that a citation of an open data article can be larger compared to its counterparts that do not have open data (Colavizza, Hrynaszkiewicz, Staden, Whitaker, \& McGillivray, 2020). 


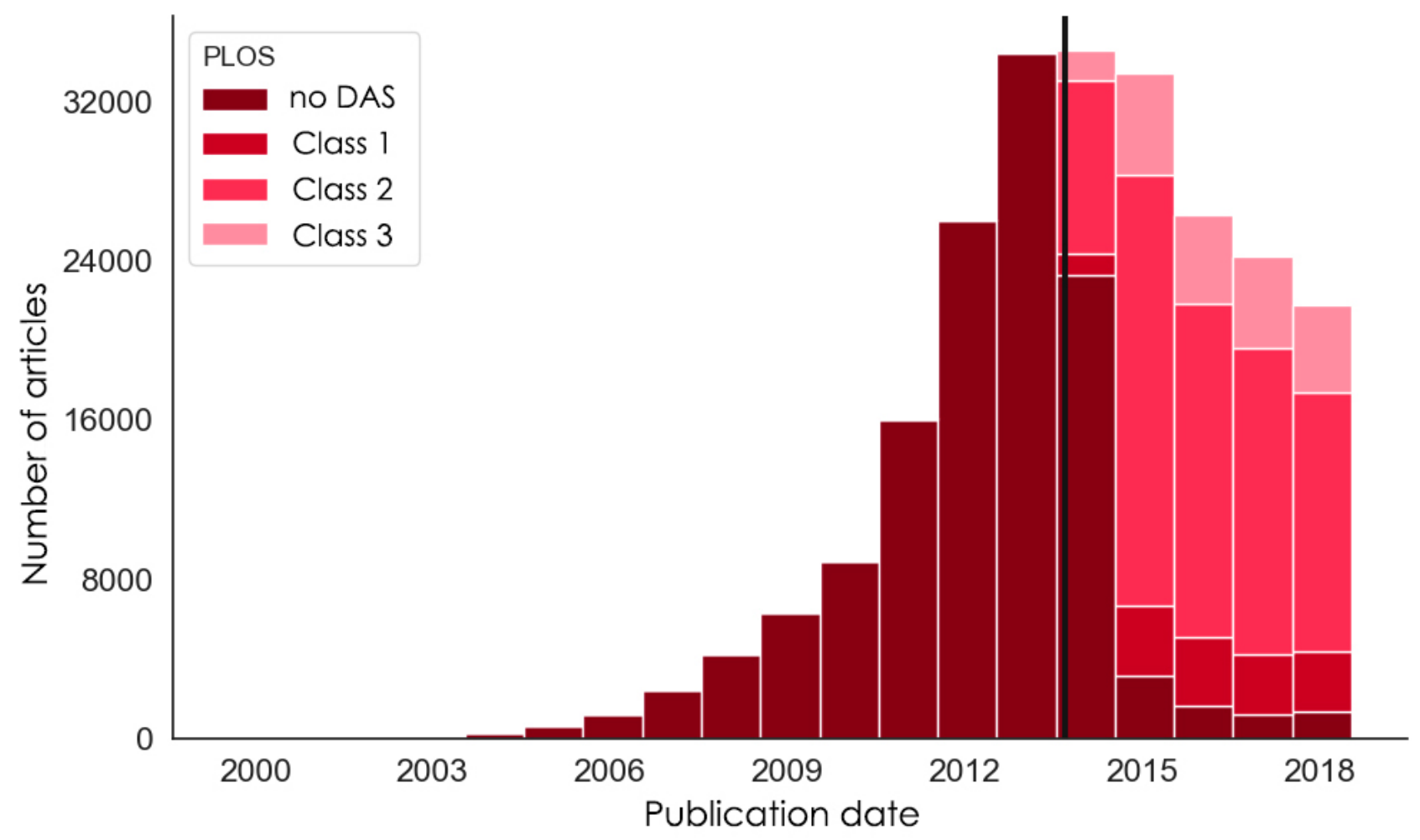

Figure 1. Evolution of categories of author discourse related to the availability of data (2004-2018) in the Public Library of Science. Source: Adapted from Knutson, D. (2020). A selfish reason to share research data. The Official Plos Blog. Retrieved from https://theplosblog.plos.org/2020/05/a-selfish-reason-to-share-research-data/.

The histogram shows the number of publications of specific subgroups of groups of data and DAS (data availability statement) categories: No DAS (0), Category 1 (data available upon request), Category 2 (data contained in the article and the complementary materials), and Category 3 (exists a link for data archived in a public repository). The solid vertical line shows the date that the mandatory DAS policy was introduced. The $R A C$, since July 2018, has strongly encouraged the practice of Category 3, maintaining a repository that centralizes data and materials used in scientific articles (https://dataverse.harvard.edu/dataverse/rac/ retrieved on June 22, 2020). In addition, articles with open data and/or materials are identified by an icon that signals the status of open data/materials.

\section{DÉJÀ LU AND OPEN DATA}

The opportunities have not been rare in which we have come across a study that gives us the sensation that we have already seen something similar at another time. And sometimes this sensation may be motivated by facts. That is, déjà lu would not be in vain. Obviously, all science is based on previously accumulated knowledge, but the additional contribution of each publication has to be clear.

At the same time, scientific societies around the world have placed the data profile as a way to elevate the level of conducted research. For example, the American Finance Association in Atlanta in January 2019 dedicated some attention to this aspect during one of its annual meetings (Giglio, Kuhnen, Baker, \& Diamond, 2019). The reuse of data is something that has great potential for effective advances in the field of knowledge. This assumption is applicable to the field of management and business research, and at the same time handles concerns with salami science (Covin \& McMullen, 2019). In addition to new studies, the reuse of data can make the enrichment of teaching activities possible as well as the training of new researchers. As Raaij (2018) points out, the Academy of Management's code of ethics contains two recommendations regarding ethical standards:

2.1.2. AOM members explicitly cite others' work and ideas, including their own, even if the work or ideas are not quoted verbatim or paraphrased. 
This standard applies whether the previous work is published, unpublished, or electronically available.

3.5. When AOM members publish data or findings that overlap with work they have previously published elsewhere, they cite these publications. AOM members must also send the prior publication or in-press work to the AOM journal editor to whom they are submitting their work (Academy of Management, 2020, online).

Raaij (2018) reports examples of problematic practices with the opportunity for successive publications based on the same database (Table 2). That is, despite the potential gain in productivity from the reuse of data (Mendes-Da-Silva, 2019a; Piwowar \& Vision, 2013; Tenopir et al., 2015; Wallis, Rolando, \& Borgman, 2013; Zimmerman, 2008), ethis procedure should be employed as long as attention is paid to the way in which the reuse of data occurs, so that it is not confused with salami science practices. Raaij (2018) points out advice to avoid incurring inappropriate practices, including:

- formulating hypotheses before the data is collected;

defining measuring instruments and multi-item constructs before the data collection;

collecting data specifically to test hypotheses in a certain study;

defining criteria for the exclusion of data before the data collection;

maintaining transparency regarding the collection instruments employed in the procedure, as well as the relevant methodological procedures.

The practice of reusing data once data from previously published studies is made available emits a signal that the author is committed to not incurring the practice of salami science. At the end, in the future this is a case when the author himself or herself will decide whether to re(use) his or her own data, in a new study with a new question that will be sufficient to bring contributions and in competition with other investigators with access to the same data. In this respect, it is not appropriate to assume that just studies of a quantitative nature will be subject to sharing data, in order to permit their future reuse. That is, there is a gamut of research opportunities that could be viable if the benefits of the reuse of qualitative data were a reality (Davidson, Edwards, Jamieson, \& Weller, 2019; Hughes, Hughes, \& Tarrant, 2020; Irwin, Bornat,
\& Winterton, 2012; Lewthwaite, Jamieson, Weller, Edwards, \& Nind, 2019; Tarrant \& Hughes, 2019).

\section{APPLICATION OF PENALTIES FOR THE PRACTICE OF SALAMI SCIENCE}

Besides warning the community about the consequences of salami science, we need to discuss the necessity and the necessary procedures to penalize this practice that harms the community and society (MojonAzzi \& Mojon, 2004; Tolsgaard, Ellaway, Woods, \& Norman, 2019). However, the imperative is to emphasize the risks of applying penalties to researchers who have not tried to inflate their numbers, as well as not penalizing researchers who wish to achieve projection without making an effective contribution.

The practice of open data can be more valuable when allied with inhibiting the inappropriate (re)use of data in multiple publications. That is, to the extent that data that supports a study is published together with the article, it is understood that this data is no longer limited to the knowledge of its authors, but rather the entire community. As a consequence, the reuse of data will be conditioned by the declaration of an original source, inhibiting the behavior of producing multiple articles without the necessary transparency of previous uses of data and mainly the effective contribution of the article based on the reuse of data (Génova, Astudillo, \& Fraga, 2016; Johnson, 2006).

Laake, Benestad and Olsen (2007) point out that in some countries there are systems dedicated to the investigation of occasional occurrences of bad scientific conduct. An example in Denmark is the Danish Committees on Scientific Dishonesty (DCSD) (https://ufm.dk/en/research-and-innovation/councilsand-commissions/The-Danish-Committee-on-ResearchMisconduct; retrieved on June 21, 2020). The application of penalties on researchers who perform the undesirable practice of the multiplicity of publications, using essentially the same data, without an incremental gain that justifies the publication, is a subject to be discussed and addressed appropriately. 
Table 2. Potential practical problems due to the reuse of data and its respective implications.

\begin{tabular}{ll}
\hline Conduct to be avoided & Resulting problem \\
\hline $\begin{array}{l}\text { Hiding of the previous } \\
\text { use of data }\end{array}$ & $\begin{array}{l}\text { Not being transparent about the existence of previous } \\
\text { publications that used the same group of data for analysis. }\end{array}$ \\
$\begin{array}{l}\text { Hiding of the age of the } \\
\text { data }\end{array}$ & Not being transparent about the age of the data. \\
$\begin{array}{l}\text { Insinuation that the data } \\
\text { collection is recent }\end{array}$ & $\begin{array}{l}\text { Suggesting that the data was collected specifically for this } \\
\text { article. }\end{array}$
\end{tabular}

Insinuation that the metrics are dedicated

Inconsistent references

Reuse of the items in an inconsistent manner

Inconsistent manner of naming constructs

Inconsistent conception of the constructs

Hiding of inconsistent exclusion of data articles without a proper explanation.

Self-contradiction without explanation

Recursive construction of hypotheses

In more recent articles using the same data, making declarations that contradicted previous publications, but without referencing previous publications.

Suggesting that the instruments/scales of measurement were developed specifically for this study.

Using the same indicators (items), and groups of indicators, for different constructs in different articles.

Using references for measuring instruments that are actually created after the data collection effort.

Using various labels for the same constructs, with they articles.

Using various groups of indicators for a construct that has the same label in a different article.

Citing a previous publication based on the same group of data with empirical support for the hypotheses developed in subsequent articles.

Recursive development of Citing a previous publication based on the same group of methods

Ignoring relevant and known conditions

Claiming falsely that there is corroboration

Declaring a false empirical contribution

Hiding the occasional evidence of inconvenient data

Hiding duplication research methods were adopted or adapted.

Suggesting that previous publications (using the same contribution (for example, a replication) for previous
Using various rules to include or exclude observations in being composed of the same indicators in different

Undesirable consequences for the community

Deficit in transparency impedes readers from properly evaluating to what extent the presented results are effectively new in relation to what has already been published.

This makes it difficult for the readers to evaluate to what extent they believe that the results are (still) valid at the time of publication.

This suggests that best practices in empirical research were followed, while in truth the sample and/or data may end up not being the best for the variables studied and for the hypotheses being tested.

This suggests that best practices in empirical research were followed, while in truth the measurement instruments may not be the most appropriate for the studied variables and the tested hypotheses.

This suggests that the measurement model may not have been defined ex ante, having been in truth created after the data was collected (and analyzed).

This suggests that the measurement model was created after the data was collected (and analyzed), and that probably the authors are capitalizing on and inflating the chance of finding significant relationships between the variables. This practice can also be used to emulate the existence of more connections of the study with more recent works that do not effectively exist.

This limits the capacity of readers to evaluate whether a construct that appears to be new is really built upon existing constructs. This makes meta-analytical studies more difficult and can end up suggesting theoretical contributions that do not really exist.

As an alternative form to the problem above, this signifies that a construct that appears to be the same is in fact a different construct. Again, this makes the accumulation of knowledge from metaanalytical studies difficult.

This suggests that the decisions taken in regard to the inclusion or exclusion of data were taken after the collection and analysis of the data, and that the authors are "massaging the data" to find significant relationships between the variables.

This suggests that the very successful publication of an individual article would be more important than its own process of the cumulative development of knowledge through these studies.

With this practice, the reader is fooled, believing that there are motives for proposing certain hypotheses, while the author(s) already know that the same group of data will support this hypothesis.

The reader could be being fooled into believing that these previous publications provide sufficient independent support for the quality of the study's research methods.
Not including variables in an article analysis, with they being considered in a previous publication. data) have corroborated the results of recent articles.

Suggesting that a later article provides an empirical publications that used the same group of data.

Discussing unmeasured items or constructs as a limitation of an article, while in other publications that use the same group of data it is clear that these items or constructs have been measured and made available.

Basically testing the same hypotheses again in a later This would be a classic case of duplicate publication or self-plagiarism. article without referencing previous publications.

The reader could be being fooled into believing that there is no knowledge of the variables that condition the presented relationships.

This practice implies suggesting the accumulation of knowledge between the studies, while this is no more than an artifice to artificially increase the credibility and contribution of a later article.

A later study can only offer an empirical contribution to a debate (for example, through a replication) when studying the same phenomenon, or relationship, using new data or methods that possess explicit comparative advantages compared to the previously employed method. This practice claims the accumulation of knowledge that does not exist.

This procedure can only be classified as a lie by the readers.

Note. Source: adapted from Raaij, E. M. V. (2018). Déjà lu: On the limits of data reuse across multiple publications. Journal of Purchasing and Supply Management, 24(3), 183-191. https://doi.org/10.1016/j.pursup.2018.06.002 


\section{THIS ISSUE}

This issue is dedicated to the inauguration of a new section of the RAC (Martins, 2021), Tutorial Articles. The implicit intention of this new section is contained in the combination of other realizations that began in mid2018 , focused on one word: transparency, together with its antecedents and consequences (Mendes-Da-Silva, 2018b). We hope that open data and the reuse of data in new studies, as well as the publication of tutorial articles, will help permit four main advances: (a) more celerity in the production of knowledge; (b) the reduction of redundant efforts in terms of the employment of modern research methods; (c) improving the standards of teaching methods in business research; (d) more space so that researchers can publish works dedicated to methods, among other positive liquid impacts in the field of business and correlated fields, such as the reduction of salami science (Pfleegor, Katz, \& Bowers, 2019).

With this, we hope to contribute so that the $R A C$ can achieve a positive incremental impact on society, bearing in mind the stimulus of the capillarity of the use of modern

\section{REFERENCES}

Adams, J., Pendlebury, D., Potter, R., \& Szomszor, M. (2019). Global research report multi-authorship and research analytics. Institute for Scientific Information. Retrieved from https://clarivate.com/webofsciencegroup/wp-content/ uploads/sites/2/dlm uploads/2019/12/WS419558643 ISI Global Research Report 6 v9 RGB SP.pdf

Academy of Management. (2020). AOM Code of Ethics. Academy of Management. Retrieved from https://aom.org/aboutaom/governance/ethics/code-of-ethics

Bell, R. K., Hill, D., \& Lehming, R. F. (2007), The changing research and publication environment in american research universities [Working Paper no SRS 07-204]. National Science Foundation, Division of Science Resources Statistics, Arlington, VA, USA. Retrieved from https:// www.immagic.com/eLibrary/ARCHIVES/GENERAL/ US NSF/N070717C.pdf

Britigan, B., Strauss, A., \& Susman, J. (2010). Salami science or editorial imperialism? Journal of Pediatrics, 157(3), 518519. https://doi.org/10.1016/j.jpeds.2010.07.034

Camargo,K.R.,Jr.(2013).Produçãocientífica:Avaliaçãodaqualidade ou ficção contábil? Cadernos de Saúde Pública, 29(9), $1707-$ 1711. https://dx.doi.org/10.1590/0102-311X00115413

Colavizza, G., Hrynaszkiewicz, I., Staden, I., Whitaker, K., \& McGillivray, B. (2020). The citation advantage of linking publications to research data. PLoS ONE, 15(4), e0230416. https://doi.org/10.1371/journal.pone.0230416 research approach techniques on the quantitative as well as qualitative side. The article by Martins (2021) provides the proper presentation of the section of old tutorial articles, as well as the works selected for this opportunity.

I would like to register here our sincere and honest personal acknowledgements to the authors of the tutorial articles that will inaugurate the $R A C$ 's new section. These people (re)acted to the public call dedicated to a relatively uncommon type of article, and this required some personal characteristics on the part of the researchers, including adaptability, entrepreneurship, patience, persistence, a willingness to take risks, and abnegation (because they could have invested their time in something closer to their comfort zone). We await new submissions of tutorial articles, and there is no shortage of subjects that need good tutorials. The researcher public and acting students are growing at a vertiginous rate, and we need to invest in the development of modern abilities that make innovative and, above all, transparent studies possible.

Good reading!

Covin, J. G., \& McMullen, J. S. (2019). Programmatic research and the case for designing and publishing from rich, multifaceted datasets: Issues and recommendations. Journal of Business Research, 101, 40-46. https://doi.org/10.1016/j.jbusres.2019.04.012

Cressey, D. R. (1953). Other people's money: A study in the social psychology of embezzlement. Glencoe, IL: Free Press.

Davey, M. (2020, June 12). Covid-19 studies based on flawed surgisphere data force medical journals to review processes. The Guardian. Retrieved from https://www.theguardian. com/world/2020/jun/12/covid-19-studies-based-onflawed-surgisphere-data-force-medical-journals-to-reviewprocesses

Davidson, E., Edwards, R., Jamieson, L., \& Weller, S. (2019). Big data, qualitative style: A breadth-and-depth method for working with large amounts of secondary qualitative data. Quality \& Quantity, 53, 363-376. https://doi.org/10.1007/s11135-018-0757-y

Eden, L., Dean, K. L., \& Vaaler, P. M. (2018). The ethical professor: A practical guide to research, teaching, and professional life. New York: Routledge.

Elstein A. S., Cadmus, C., Pitkin, R., Mundy, D., \& McDowell, C. (1998). Salami science: Are we still allowing it? CSE Annual Meeting Reports. Retrieved from http:// www.councilscienceeditors.org/wp-content/uploads/ v21n6p200.pdf 
Engle, C. R. (2018). Evaluation of contributions of aquaculture researchers: The need to change researcher incentives to reduce salami science in aquaculture. Journal of the World Aquaculture Society, 49(6), 968-970. https://doi.org/10.1111/jwas.12577

Feeg, V. D. (1992). Duplicate publication or salami science? Pediatric Nursing, 18(6), 550. Retrieved from https://pubmed.ncbi.nlm.nih.gov/1470485/

Génova,G.,Astudillo,H., \&Fraga,A. (2016). Thescientometricbubble considered harmful. Science and Engineering Ethics, 22(1), 227-235. https://doi.org/10.1007/s11948-015-9632-6

Giglio, S., Kuhnen, C., Baker, S., Diamond, R. (2019, January 25). New datasets and methods in finance research [Video file]. Video posted to https://youtu.be/-cWeU1VfoMw

Gomes, H. (2020, June 06). Covid-19. Publicaçōes científicas forçadas a reconsiderar processos de revisão após estudos com dados "seriamente defeituosos". Expresso. Retrieved from https://expresso.pt/coronavirus/2020-06-12-Covid19.-Publicacoes-cientificas-forcadas-a-reconsiderarprocessos-de-revisao-apos-estudos-com-dadosseriamente-defeituosos

Hoit, J. D. (2007). Salami science. American Journal of Speech-Language Pathology, 16(2), 94. https://doi.org/10.1044/1058-0360(2007/013)

Honig, B., Lampel, J., Siegel, D., \& Drnevich, P. (2014). Ethics in the production and dissemination of management research: Institutional failure or individual fallibility? Journal of Management Studies, 51(1), 118-142. https://doi.org/10.1111/joms.12056

Hughes, K., Hughes, J., \& Tarrant, A. (2020). Re-approaching interview data through qualitative secondary analysis: Interviews with internet gamblers. International Journal of Social Research Methodology. https://doi.org/10.1080/13645579.2020.1766759

Irwin, S., \& Winterton, M. (2012). Qualitative secondary analysis: A guide to practice. Timescapes Methods Guides Series 2012 [Guide no 19]. Retrieved from http://www. timescapes.leeds.ac.uk/assets/files/methods-guides/ timescapes-irwin-secondary-analysis.pdf

Irwin, S., Bornat, J., \& Winterton, M. (2012). Timescapes secondary analysis: Comparison, context and working across data sets. Qualitative Research, 12(1), 66-80. https://doi.org/10.1177\%2F1468794111426234

Jackson, D., Walter, G., Daly, J., \& Cleary, M. J. (2014) Editorial: multiple outputs from single studies: acceptable division of findings vs. 'salami' slicing. Journal of Clinical Nursing, 23(1-2): 1-2. https://doi.org/10.1111/jocn.12439

Johnson, C. (2006). Repetitive, duplicate, and redundant publications: A review for authors and readers. Journal of Manipulative and Physiological Therapeutics, 29(7), 505509. https://doi.org/10.1016/j.jmpt.2006.07.001

Karabag, S. F., \& Berggren, C. (2016). Misconduct, marginality and editorial practices in management, business and economics journals. PLoS ONE, 11(7), e0159492. https://doi.org/10.1371/journal.pone.0159492
Knutson, D. (2020, May). A selfish reason to share research data. The Official Plos Blog. Retrieved from https://theplosblog. plos.org/2020/05/a-selfish-reason-to-share-research-data/

Laake, P., Benestad, H. B., \& Olsen, B. R. (2007). Research methodology in the medical and biological sciences. New York: Elsevier.

Lewthwaite, S., Jamieson, L., Weller, S., Edwards, R. \& Nind, M. (2020). Teaching how to analyse large volumes of secondary qualitative data. National centre for research methods online learning resource. Retrieved from https://www.ncrm.ac.uk/resources/online/teaching big qual/

Martins, H. C. (2021). Tutorial-articles: The importance of data and code sharing. Revista de Administraçâo Contemporânea, 25(1), e200212. https://doi.org/10.1590/1982-7849rac2021200212

Mendes-Da-Silva, W. (2018a). Reconhecimento da contribuição do avaliador anônimo. Revista de Administração Contemporânea, 22(5). https://doi.org/10.1590/1982-7849rac2018180281

Mendes-Da-Silva, W. (2018b). The promotion of transparency and the impact of research on business. Revista de Administração Contemporânea, 22(4), 639-649. https://doi.org/10.1590/1982-7849rac2018180210

Mendes-Da-Silva, W. (2019a). Meus dados, minha vida: Objetivos individuais e papel da comunidade de pesquisadores na área de negócios. Revista de Administração Contemporânea, 24(2), 197-200. https://doi.org/10.1590/1982-7849rac2020190403

Mendes-Da-Silva, W. (2019b). Temos sido transparentes o suficiente? Desafios à replicabilidade e à credibilidade da pesquisa na área de negócios. Revista De Administraçâo Contemporânea, 23(5). https://doi.org/10.1590/1982-7849rac2019190306

Mojon-Azzi, S. M., \& Mojon, D. S. (2004). Scientific misconduct: From salami slicing to data fabrication. Ophthalmic Research, 36(1), 1-3. https://doi.org/10.1159/000076104

Nature Materials. (2005). The cost of salami slicing. Nature Materials, 4(1), 1. https://doi.org/10.1038/nmat1305

Perlin, M. S., Imasato, T., \& Borenstein, D. (2018). Is predatory publishing a real threat? Evidence from a large database study. Scientometrics, 116(1), 255-273. https://doi.org/10.1007/s11192-018-2750-6

Pfleegor, A. G., Katz, M., Bowers, M. T. (2019). Publish, perish, or salami slice? Authorship ethics in an emerging field. Journal of Business Ethics, 156(1), 189-208. https://doi.org/10.1007/s10551-017-3578-3

Piwowar,H.A., \&Vision, T.J.(2013).Data reuseand theopendatacitation advantage. PeerJ, 1, e175. https://doi.org/10.7717/peerj.175

Pohlmann, M. (2019). Publish and perish? The business of predatory publishers and output orientation in science. Heigos Blog. Retrieved from https://heigos.hypotheses.org/11687

Raaij, E. M. V. (2018). Déjà lu: On the limits of data reuse across multiple publications.JournalofPurchasingandSupplyManagement, 24(3), 183-191. https://doi.org/10.1016/j.pursup.2018.06.002 
Rupp, M., Anastasopoulou, L., Wintermeyer, E., Malhaan, D., El Khassawna, T., \& Heiss, C. (2019). Predatory journals: A major threat in orthopaedic research. International Orthopaedics, 43(3), 509-517. https://doi.org/10.1007/s00264-018-4179-1

Smolčić, V. Š. (2013). Salami publication: Definitions and examples. Biochemia Medica, 23(3), 237-241. http://dx.doi.org/10.11613/BM.2013.030

Stuebs, M., \& Wilkinson, B. (2010). Ethics and the tax profession: Restoring the public interest focus. Accounting and Public Interest, 10(1), 13-35. https://doi.org/10.2308/api.2010.10.1.13

Tarrant, A., \& Hughes, K. (2019). Qualitative secondary analysis: building longitudinal samples to understand men's generational identities in low income contexts. Sociology, 53(3), 538-553. https://doi.org/10.1177/0038038518772743

Tarrant, A. (2017). Getting out of the swamp? Methodological reflections on using qualitative secondary analysis to develop research design. International Journal of Social Research Methodology, 20(6), 599-611. https://doi.org/10.1080/13645579.2016.1257678

Tenopir, C., Dalton, E. D., Allard, S., Frame, M., Pjesivac, I., Birch, B., Pollock, D., \& Dorsett, K. (2015) Changes in data sharing and data reuse practices and perceptions among scientists worldwide. PLoS ONE, 10(8), e0134826. https://doi.org/10.1371/journal.pone.0134826

\section{Authorship}

\section{Wesley Mendes-Da-Silva*}

Fundação Getulio Vargas, Escola de Administração de Empresas de São Paulo.

Rua Itapeva, 474, $8^{\circ}$ andar, 01332-000, São Paulo, SP, Brazil.

E-mail address: rac.wesley.mendes@gmail.com

(D) https://orcid.org/0000-0002-5500-4872

\section{Cristiana Cerqueira Leal}

Escola de Economia e Gestão, Universidade do Minho.

Rua Bairro do Sol, no 4, 4710-057, Braga, Portugal.

E-mail address: ccerqueira@eeg.uminho.pt

(D) https://orcid.org/0000-0003-3731-0240

* Corresponding author
Tolsgaard, M. G., Ellaway, R., Woods, N., \& Norman, G. (2019). Salami-slicing and plagiarism: How should we respond?. Advances in Health Sciences Education, 24, 3-14. https://doi.org/10.1007/s10459-019-09876-7

Wallis, J. C., Rolando, E., Borgman, C. L. (2013). If we share data, will anyone use them? Data sharing and reuse in the long tail of science and technology. PLoS ONE, 8(7), e67332. https://doi.org/10.1371/journal.pone.0067332

Watson, R., Pickler, R., Noyes, J., Perry, L., Roe, B., Hayter, M., $\&$ Hueter, I. (2014). How many papers can be published from one study? Leading Global Nursing Research, 71(11), 2457-2460. https://doi.org/10.1111/jan.12600

Wawer, J. (2019). How to stop salami science: Promotion of healthy trends in publishing behavior. Accountability in Research, 26(1), 33-48. https://doi.org/10.1080/08989621.2018.1556099

White, K. (2019). Publication output, by region, country, or economy. Science \& Engineering Indicators. Retrieved from https://ncses.nsf.gov/pubs/nsb20206/publication-outputby-region-country-or-economy

Zimmerman, A. S. (2008). New knowledge from old data: The role of standards in the sharing and reuse of ecological data. Science, Technology, \& Human Values, 33(5), 631-652. https://doi.org/10.1177/0162243907306704

\section{Conflict of Interest}

The authors have stated that there is no conflict of interest.

\section{Copyrights}

RAC owns the copyright to this content.

\section{Plagiarism Check}

The RAC maintains the practice of submitting all documents approved for publication to the plagiarism check, using specific tools, e.g.: iThenticate. 


\section{SCIENTIFIC EDITORIAL BOARD AND EDITORIAL TEAM FOR THIS ISSUE:}

\section{Editorial Council}

Anielson Barbosa da Silva (UFPB, João Pessoa, Brazil)

Antonio Carlos Gastaud Maçada (UFRGS, Porto Alegre, Brazil)

Ely Laureano Paiva (FGV, São Paulo, Brazil)

Fabio Vizeu Ferreira (UP, Curitiba, Brazil)

Maria José Tonelli (FGV, São Paulo, Brazil)

Rogério Hermida Quintella (NPGA/UFBA, Salvador, Brazil)

Valmir Emil Hoffmann (UnB, Brasília, Brazil)

Wesley Mendes-da-Silva (FGV/ EAESP, São Paulo, Brazil)

\section{Editor-in-chief}

Wesley Mendes-da-Silva (FGV/ EAESP, São Paulo, Brazil)

\section{Associate Editors}

Fabio Caldieraro (EBAPE/FGV, São Paulo, Brazil)

Gilnei Luiz de Moura (UFSM, Santa Maria, Brazil)

Henrique Castro Martins (IAG PUC-Rio, Rio de Janeiro, Brazil)

Ismael Ali Ali (Kent State University, Ohio, USA)

Marcus Cunha Junior (University of Georgia, USA)

Paula Castro Pires de Souza Chimenti (UFRJ/Coppead, Rio de Janeiro, Brazil)

Paulo César Matui (UniGranRio, Rio de Janeiro, Brazil)

Samy Dana (FGV/EAESP, São Paulo, Brazil)

\section{Scientific Editorial Board}

André Luiz Maranhão de Souza-Leão (UFPE, Recife, Brazil) Aureliano Angel Bressan (CEPEAD/UFMG, Belo Horizonte, Brazil) Bryan Husted (York University, Canada)

Carlos M. Rodriguez (Delaware State University, USA)

Cristiana Cerqueira Leal (Universidade do Minho, Portugal)

Diógenes de Souza Bido (Mackenzie, São Paulo, Brazil)
Erica Piros Kovacs (Kelley School of Business/Indiana University, USA)

Elin Merethe Oftedal (University of Tromsø, Norway)

Emilio Jose Monteiro Arruda Filho (Unama, Belém, Brazil)

Fábio Frezatti (FEA/USP, São Paulo, Brazil)

Felipe Monteiro (Wharton/University of Pennsylvania, USA)

Howard J. Rush (University of Brighton, United Kingdom)

James Robert Moon Junior (Georgia Institute of Technology, USA)

John L. Campbell (University of Georgia, USA)

José Antônio Puppim de Oliveira (United Nations University,

Yokohama, Japan)

Julián Cárdenas (Freie Universität, Berlin, Germany)

Lucas Barros (FEA/USP, São Paulo, Brazil)

Luciano Rossoni (UniGranRio, Rio de Janeiro, Brazil)

M. Philippe Protin (Université Grenoble Alpes, France)

Paulo Estevão Cruvinel (Embrapa Instrumentação, São Carlos, Brazil)

Rodrigo Bandeira de Mello (Merrimack College, USA)

Rodrigo Verdi (MIT Massachusetts Institute of Technology, Cambridge, USA)

Valter Afonso Vieira, (UEM, Maringá, Brazil)

Wagner Kamakura (Jones Graduate School of Business, Rice University, Houston, USA)

\section{Editing}

Typesetting and normalization to APA standards: Kler Godoy (ANPAD, Maringá, Brazil); Simone L. L. Rafael (ANPAD, Maringá, Brazil).

Frequency: Continuous publication.

Circulation: Free open access to the full text.

Indexing and Directories

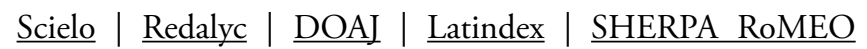
Cengage/GALE | Econpapers | EBSCO | MIAR | Proquest SPELL $\mid$ Cabell's | Ulrichs $\mid$ CLASE | DIADORIM | ERIHPlus |

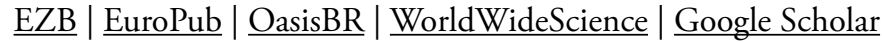
| Capes/Qualis 